Research Article

\title{
Land Circulation, Scale Operation, and Agricultural Carbon Reduction Efficiency: Evidence from China
}

\author{
Haonan Song $\mathbb{D}^{D}$, Hui Jiang $\mathbb{D}^{\mathbb{D}}$, Shiyun Zhang $\mathbb{D}^{D}$, and Jingdong Luan \\ College of Economics \& Management, Anhui Agricultural University, Hefei 230031, China \\ Correspondence should be addressed to Haonan Song; haonanjg@stu.ahau.edu.cn
}

Received 3 September 2021; Revised 17 September 2021; Accepted 20 September 2021; Published 30 September 2021

Academic Editor: Daqing Gong

Copyright $\odot 2021$ Haonan Song et al. This is an open access article distributed under the Creative Commons Attribution License, which permits unrestricted use, distribution, and reproduction in any medium, provided the original work is properly cited.

\begin{abstract}
Based on the panel data of 30 Chinese province in 2005-2018, this paper quantifies agricultural carbon reduction efficiency (CRE), using the slack-based measure (SBM)-data envelopment analysis (DEA) model with undesired outputs (SBM-DEA*), and empirically tests that development of land circulation market directly affects agricultural CRE, and indirectly affects agricultural CRE via scale operation of farmland. The results show that the following: (1) In the observation period, China's agricultural CREs generally evolved from a low level to a high level, with an annual growth rate of $8.0 \%$, but there is still a large space of carbon reduction. (2) Overall, land circulation significantly promoted agricultural CRE, but the promoting effect varied from region to region: the promoting effect was significant in eastern and central regions, and insignificant in western region. (3) Scale operation of farmland had a nonlinear, partial mediation effect on how land circulation influences agricultural CRE; land circulation greatly accelerated the scale operation of farmland, while the growing scale of farmland utilization had an inverted U-shaped influence on agricultural CRE. Our research results imply that promoting land circulation directly drives the low-carbon transformation of agriculture in China, but excessive scale operation of farmland might hinder agricultural carbon reduction.
\end{abstract}

\section{Introduction}

Since the reform and opening-up, China has made great achievements in agricultural development. Nearly $20 \%$ of the world population are raised with less than $8 \%$ of global farmlands. The once starving Chinese people soon had adequate food and clothing and now enjoy a well-off life. However, the extensive use of means of production like fertilizers, pesticides, and agricultural machinery has brought increasingly serious problems to the eco-environment. From 1978 to 2018, the fertilizer consumption in China grew from 8.84 million tons to 56.53 million tons, while only $37.8 \%$ of fertilizers were effectively utilized by major crops [1]. Lots of fertilizers were not absorbed but flowed outside via surface runoff and farmland leakage.

Under the high-input and low-efficiency mode of agricultural development, China becomes the largest agricultural carbon emitter in the world [2]. The Intergovernmental Panel on Climate Change (IPCC) estimates that agriculture is the second largest source of global greenhouse gas emissions (GHGs), taking up 14\% of global GHGs emissions. In China, agriculture contributes $17 \%$ of the total GHGs emissions [3]. The Chinese government has pledged to peak its carbon emissions in 2030 and realize carbon neutralization in 2060. Against this backdrop, it is important to promote modern agriculture and ecological civilization through low-carbon agricultural transformation, while ensuring the stable and efficient supply of agricultural products.

"A big country with many smallholder farmers" is a basic national condition of China. To modernize agriculture, China must promote land circulation and pursue scale operation [4]. Bearing in mind this inevitable path to agricultural modernization, China has gradually reformed farmland property rights by extending contact period, registering the contracted lands, and separated the ownership rights, contract rights, and management rights of farmlands, with the aim to develop land circulation market by clarifying land ownership [5]. Statistics from Chinese Ministry of Agriculture and Rural Affairs show that, at the 
end of 2019, land circulation covered more than 560 million mu of farmlands [6], about $40 \%$ of all contracted farmlands in the country.

Farmland circulation plays active roles in many aspects of social economy, such as enhancing agricultural efficiency [7], guaranteeing food security [8], and raising farmer income [9], and makes immense contributions to agricultural modernization. Nevertheless, some scholars fear that land circulation could push up the carbon emissions in agriculture: owing to the incomplete land ownership, the profitseeking subjects operating on the transferred farmland might manipulate the externalities of the eco-environment to lower production cost, which leads to shortsighted behaviors like overuse of land resources and intense application of chemicals $[10,11]$. Their views are countered by some other scholars. For example, Liang et al. [12] found that land circulation significantly suppresses farmers' chemical input intensity, through a survey on farmers in Central China's Hubei Province. Kuang and Zhang [13] learned that land circulation greatly improves agricultural environmental efficiency. The above literature review indicates that the academia still disagrees on whether land circulation helps us to reduce agricultural carbon emissions.

Besides, it is noteworthy that land circulation spurs the scale operation of farmland, which in turn transforms land utilization and impacts agricultural carbon emissions. This causal chain has attracted much attention from researchers but led to inconsistent results. Some scholars held that the scale operation of farmland, which relies heavily on chemical synthetics, weakens the natural bound between agriculture and ecology, and aggravates agricultural carbon emissions and environmental pollution [14]. Some scholars believed that low-carbon operation faces major obstacles amidst the small-scale peasant economy, e.g., the poor tolerance of small farmers for market risks, and the high operating cost per unit of farmland, and advocated promoting low-carbon agriculture through scale operation [15]. Some other scholars argued that scale operation does not have a simple linear relationship with agricultural carbon emissions. Based on microsurvey data, Ye et al. [16] discovered the inverted $\mathrm{U}$-shaped relationship between operating scale and lowcarbon production behaviors of farmers. By measuring panel data, Liu and Xiao [17] noticed the U-shaped relationship between operating scale and agricultural carbon emissions.

In the pursuit of beautiful China, carbon peaking, and carbon neutralization, it is of great theoretical and practical significance to clarify how the development of land circulation market and scale operation of farmland influences agricultural carbon reduction. The relationship between the three factors needs to be reexamined and tested to solve the controversies among researchers:

(1) There is a causal effect between the development of land circulation market and scale operation of farmland. The two factors act on low-carbon agricultural development differently. It is impossible to correctly estimate the influence of one factor over agricultural carbon reduction, without considering the correlations and differences between the two factors.

(2) The existing studies mostly evaluate the level of agricultural carbon reduction from the angles of regional agricultural carbon emissions or farmers' factor inputs, failing to regard agriculture as a complex system with multiple inputs and outputs. The carbon reduction level of agricultural production system has not been evaluated scientifically.

(3) On the data level, most studies adopt the crosssectional survey data on the farmers in a region. The lack of comprehensiveness dampens the effectiveness and robustness of empirical results and cannot disclose the law of macroeconomy.

To address the above problems, this paper utilizes the panel data of 30 Chinese provinces in 2005-2018 and quantifies the agricultural carbon reduction efficiency (CRE), using slack-based measure (SBM)-data envelopment analysis (DEA) model with undesired outputs (SBM-DEA*). On this basis, a mediating effect analysis framework was set up and used to empirically verify how development of land circulation market directly affects agricultural CRE and indirectly affects agricultural CRE via scale operation of farmland. The research findings enrich our understanding of land circulation effects and lay a theoretical basis for formulating policies on agricultural low-carbon transformation.

\section{Methodology}

As a popular concept in to industrial and urban economic sectors, CRE is often used to measure the gap between actual carbon emissions and optimal carbon emissions generated by manufacturers or human economic activities [18, 19]. Drawing on this concept, agricultural CRE was defined as the ratio of theoretical minimum carbon emissions to actual carbon emissions of agricultural production activities, under fixed inputs and outputs. Agricultural CRE directly reflects the effect of regional agricultural carbon emissions and indirectly reflects the potential of the region in agricultural carbon emissions.

The loss of agricultural CRE mainly comes from falling output, redundant inputs of carbon sources, and lag in technology. Therefore, this paper assumes that the development of land circulation market not only directly improves agricultural CRE, but also exerts a nonlinear, indirectly impact on agricultural CRE via the scale operation of farmland.

2.1. Land Circulation and Agricultural CRE. China implements the household responsibility system, which serves the goal of "land to the tiller." Under this system, farmlands are evenly distributed to farmer households, based on distance, land fertility, and population. Thus, the initial distribution of 
land resources in rural China is highly fragmented [20]. The existing studies have shown that the even distribution under the household responsibility system ignores the heterogenous agricultural production abilities among farmer households, making it difficult for farmers to reasonably allocate labor between agriculture and nonagricultural sectors, in the light of their comparative advantages. This leads to the mismatch between land and labor [21-23]. In theory, the mismatch of means of production directly suppresses outputs and distorts the input decisions of microsubjects, causing the loss of environmental welfare $[24,25]$.

In essence, land circulation is the constant optimization of the allocation of land and labor, two basic factors of agricultural production. With the development of land circulation market, high-efficiency, capable producers often operate more lands, while inefficient producers will transferout some lands, and even fully switch to nonagricultural sectors [26]. Under the microscale efficiency driving mechanism, the development of the land circulation market transforms the agricultural operation pattern from "land to the tiller" to "land to the capable," enhancing the overall agricultural technical efficiency in the region. There are many benefits of this transformation: the land utilization will be increased to reduce the agricultural output loss [27, 28]; the extensive factor input will become more intensive and efficient, which promotes the reduction of agricultural inputs [29]; the agricultural CRE will be improved through the optimization of input-output combinations.

Apart from the optimization of input-output combinations, the application of low-carbon agricultural technology also contributes to agricultural CRE improvement. The theory of technology diffusion holds that the application of a technology not only depends on technical attribute and environmental constraint, but also hinges on the features of the group that adopt the technology [30]. Agricultural producers prefer the technologies with good attributes and in line with their endowment constraint [31]. Existing studies have shown that, compared with general farmers, the operators of transfer-in lands boast a strong operating capability, rich production experience, and high professional level. They are more likely to accept and adopt low-carbon agricultural technology [32-34]. The growing rural land circulation rate will push up the proportion of rural land resources allocated to transfer-in parties. This helps us to speed up the use and spread of low-carbon agricultural technology, which in turn improves the agricultural CRE.

2.2. Land Circulation, Scale Operation of Farmland, and Agricultural CRE. Studies have shown that, under the intense labor-land relationship, farmland management rights should be reallocated to realize scale operation of farmland, and the development of land circulation market could greatly improve the scale operation of farmland management [35]. The development of scale operation of farmland stitches up the fragmented farmland management system, forming the scale economy that improves agricultural CRE.
The scale economy refers to the long-term mean cost per unit product decreases with the expanding production scale, under the fixed production conditions. In industry, the production scale is described by output. In agriculture, the production scale is usually expressed as farmland scale.

First, the expansion of farmland scale stimulates producers' demand for agricultural means of production like fertilizers and pesticides. Through bulk purchases of agricultural means of production, producers gain the bargaining power and reinforce information collection and quality screening, aiming to prevent adverse selection behaviors like excessive input of chemicals [36].

Second, another benefit of scale operation of farmland is land integration, making it easier and cheaper to replace labor with machines. Studies have shown that scale operation of farmland effectively alleviates land fragmentation. Compared with small plots, large plots require a relatively low fuel consumption for agricultural machinery operations [37].

Third, progress of agricultural technology is the key to boosting CRE, and the application of new technologies is premised on a relatively large farmland scale. In practice, a certain scale of farmlands lays the foundation for implementing green prevention and control, soil fertilization, fertigation, water-saving irrigation, and other low-carbon agriculture technologies [38]. Since infrastructure is inseparable from agricultural technology input, the growing scale of farmlands gives play to the spatial spillover effect, lower the transformation cost of production mode, and push up agricultural CRE.

Nonetheless, diseconomies of scale might occur when farmlands surpass a certain scale, for farmland scale needs to adapt to the operating ability and management quality of producers. Studies have shown that, with the expansion of farmland scale, the input intensities of agricultural factors first decrease and then increase. Specifically, the input intensities of agricultural carbon sources (e.g., fertilizers and chemicals) exhibit an obvious $\mathrm{U}$-shaped trend, with the changes in farmland scale [39, 40]. That is, the expansion of farmland scale, as long as it falls within a certain interval, helps us to promote agricultural CRE. Once the scale surpasses a threshold, any growth of farmland scale will induce the loss of agricultural CRE.

The above analysis shows that land circulation has a twofold influence on agricultural CRE. For one thing, land circulation corrects the mismatch between factors and directly improves agricultural CRE. For another, land circulation promotes the scale operation of farmland and indirectly impacts agricultural CRE through the realization and diffusion of agricultural scale economy; the indirect impact takes the shape of an inverted U. As China is reshaping its labor-land relationship; the land circulation is largely informal, relatively closed, and weakly marketized [41]. The scale operation of farmland is not mature, and agricultural production is still dominated by small farmers. Hence, the scale economy has not been realized for the scale operation of farmland in China. Overall, the development of land circulation market is expected to positively affect agricultural CRE. 


\section{Models, Variables, and Data}

\subsection{Econometric Models}

3.1.1. SBM-DEA*. By definition, agricultural CRE should be measured with the actual level of agricultural carbon emissions, as well as the theoretical optimal carbon emissions. With the aid of DEA, this paper builds up a multi-input, multi-output agricultural production system. DEA is a nonparametric efficiency measurement method that judges whether decision-making units (DMUs) in the same category are efficient in production, using linear programming. Traditionally, the DEA model solves the efficiency based on proportional reduction of inputs or proportional expansion of outputs (i.e., radial and angle), failing to consider the slackness of inputs or outputs. Neither are undesired outputs of production included in the evaluation system. As a result, the efficiency measured by traditional DEA is biased or inaccurate. Agriculture is a complex production system involving multiple inputs and outputs. The input factors like land, labor, and capital not only form a desired output (agricultural output), but inevitably produce an undesired output (agricultural carbon emissions). The traditional DEA cannot measure the efficiency decrement caused by the undesired output.

To solve the problem, this paper uses Tone's SBM-DEA* to measure agricultural CRE [42]. The SBM-DEA* prevents the bias induced by radial and angle selection by allowing disproportional increase/decrease of the input and output slack variables for each DMU. Moreover, the projection of the undesired output on the efficient frontier can be decomposed from the measured slack variables, and used to derive the efficiency decrement caused by the undesired output [43]. The previous studies have relied on SBM-DEA* to measure urban PM2.5 emission reduction [44] and logistics CRE [45]. Hence, SBM-DEA* is suitable for estimating agricultural CRE.

Our empirical analysis targets the panel data of Chinese provinces. There may be differences in the production possibility set (PPS) between provinces in different periods. It is difficult to compare the efficiencies measured against the efficient frontiers at different moments. Drawing on Pastor and Lovell [46] global comparison strategy, this paper sets up the optimal efficient frontier based on the agricultural input and output data of all provinces in the observation period and takes it as the uniform benchmark to obtain the efficiency of each DMU, making the efficiencies comparable across periods.

Following the global comparison strategy, each province in each year is regarded as a unique DMU. It is assumed that each DMU produces $s$ desired outputs and $u$ undesired outputs from $m$ inputs. Under variable returns to scale (VRS), the general form of SBM-DEA* can be constructed as

$$
\begin{aligned}
& \min \rho=\frac{1+(1 / m) \sum_{i=1}^{m}\left(s_{i}^{-} / x_{i 0}\right)}{1-(1 /(s+u))\left(\sum_{i=1}^{s}\left(s_{i}^{g} / y_{i 0}^{g}\right)+\sum_{i=1}^{u}\left(s_{i}^{b} / y_{i 0}^{b}\right)\right)} \\
& \text { s.t. }\left\{\begin{array}{l}
x_{0}=X \lambda+s^{-} \\
y_{0}^{g}=Y^{g} \lambda-s^{g} \\
y_{0}^{b}=Y^{b} \lambda+s^{b} \\
\lambda \geq 0, s^{-} \geq 0, s^{g} \geq 0, s^{b} \geq 0
\end{array}\right.
\end{aligned}
$$

where $\rho$ is the objective function; $s^{-}, s^{\mathrm{g}}$, and $s^{\mathrm{b}}$ are the slack variables of inputs, desired outputs, and undesired outputs; $\lambda$ is weight. According to the definition of agricultural CRE (the ratio of minimum possible carbon emissions to actual carbon emissions of agricultural production, under fixed inputs and economic outputs), when agricultural carbon emissions is the only one undesired output, the annual agricultural CRE of each province can be measured with the slack variables of total agricultural carbon emissions by solving the linear programming model (1):

$$
\mathrm{CRE}=\frac{y_{0}^{b}-s^{b}}{y_{0}^{b}},
$$

where $y_{0}^{b}$ is the actual agricultural carbon emissions; $s^{b}$ is the slack variable of agricultural carbon emissions; and $y_{0}^{b}-s^{b}$ is the theoretical optimal agricultural carbon emissions. The value of CRE falls in $[0,1]$. The smaller the CRE, the greater the deviation of the actual carbon emissions of agricultural production from the minimum possible carbon emissions, the more redundant the agricultural carbon emissions, and the lower the efficiency of carbon reduction. If $C R E=1$, then the slack variables of agricultural carbon emissions are zero. In this case, the input-output combination of agricultural production system falls right on the efficient frontier, and the agricultural carbon emissions reach the theoretical minimum.

3.1.2. Mediating Effect Model. The mediating effect model was proposed by Baron and Kenny [47]. Rather than solely explore the influence of explanatory variables on explained variables, the mediating effect model can accurately disclose the internal mechanism of the casual chain, identify the interaction between phenomena, and clarify the complex relationships among interactors, enabling policymakers to take pertinent policies as per the direction and strength of mediating effect. In the field of economics, the mediating effect model has become immensely popular in empirical research, owing to its inclusiveness and in-depthness [48].

Concerning the influence of explanatory variable $X$ on explained variable $Y$, if $X$ not only directly affects $Y$, but also indirectly impacts $Y$ via $M$, then $M$ is a mediator variable. The previous analysis shows land circulation both directly 
affect agricultural CRE, but also exert an indirect nonlinear effect on the latter via scale operation of farmlands. This means scale operation is a mediator variable of the influence from land circulation on agricultural CRE. Therefore, this paper uses the mediating effect model to verify the action mechanism of land circulation on agricultural CRE, after measuring the agricultural CRE. The mediating effect model consists of three hierarchical regression models:

$$
\begin{aligned}
\mathrm{CRE}_{\mathrm{it}} & =a_{0}+a_{1} \operatorname{Tra}_{\mathrm{it}}+a_{2} \operatorname{Control}_{\mathrm{it}}+\mu_{1 i}+\gamma_{1 t}+e_{1 i t}, \\
\mathrm{Sca}_{\mathrm{it}} & =b_{0}+b_{1} \operatorname{Tra}_{\mathrm{it}}+b_{2} \text { Control }_{\mathrm{it}}+\mu_{2 i}+\gamma_{2 t}+e_{2 \mathrm{it}}, \\
\mathrm{CRE}_{\mathrm{it}} & =c_{0}+c_{1} \operatorname{Tra}_{i}+c_{2} \mathrm{Sca}_{\mathrm{it}}+c_{3} \mathrm{Sca}_{\mathrm{it}}^{2}+c_{4} \operatorname{Control}_{\mathrm{it}}+\mu_{3 i}+\gamma_{3 t}+e_{3 \mathrm{it}},
\end{aligned}
$$

where $i$ is a region; $t$ is a period; CRE is the agricultural CRE; Tra is the land circulation; Sca is the scale operation; Control is the series of control variables; $a_{0} \sim a_{2}, b_{0} \sim b_{2}$, and $c_{0} \sim c_{3}$ are the parameters to be estimated; $\mu_{1 i} \sim \mu_{3 i}$ is the region fixed effects; $\gamma_{1 i} \sim \gamma_{3 i}$ is the time fixed effects; and $e_{1 \text { it }} \sim e_{3 i t}$ are the random errors.

Formula (3) is the benchmark regression model, where coefficient $a_{1}$ depicts the overall influence of land circulation over agricultural CRE. Formula (4) estimates the influence of core explanatory variable on the meditator variable, where coefficient $b_{1}$ depicts the influence of land circulation on scale operation. Formula (5) introduces core explanatory variable, mediator variable, and its square term, in addition to controlling the other variables. In this formula, coefficient $c_{1}$ reflects the direct influence of land circulation over agricultural CRE; coefficients $c_{2}$ and $c_{3}$ capture the nonlinear effect of farmland scale on agricultural CRE. According to the analysis framework of mediating effect, if $a_{1}, b_{1}, c_{1}, c_{2}$, and $c_{3}$ are all significant, then land circulation both directly influence agricultural CRE and exert a nonlinear, indirect impact on agricultural CRE via scale operation.

\subsection{Variable Settings}

3.2.1. Explained Variable. Agricultural CRE is the explained variable in our empirical analysis and measured by SBMDEA*.

The inputs of SBM-DEA* include total sown area of crops, total power of agricultural machinery, consumption of fertilizers converted to pure amount, and the total labor of planting industry. The total labor of planting industry is not mentioned in national or provincial statistical yearbooks. Referring to the existing studies, the ratio of agricultural output to agriculture, forestry, animal husbandry, and fishery (AFAF) output was taken as the conversion weight, and multiplied with the total labor force of primary industry to approximate the total labor of planting industry.

The outputs of SBM-DEA* include a desired output, the total output of planting industry, and an undesired output, agricultural carbon emission. To prevent index meaning from being distorted by price fluctuations and ensure the comparison across periods, the total output of planting industry was deflated with 2005 as the base period. Agricultural carbon emission was measured with the carbon emission coefficients specified by IPCC. Six carbon sources were taken into account: fertilizers, pesticides, diesel, mulching, irrigation, and ploughing. According to Ma et al. [49], the conversion coefficients of the six carbon sources were set to $0.89 \mathrm{~kg} / \mathrm{kg}, 4.93 \mathrm{~kg} / \mathrm{kg}, 0.59 \mathrm{~kg} / \mathrm{kg}, 5.18 \mathrm{~kg} / \mathrm{kg}$, $25 \mathrm{~kg} / \mathrm{hm}^{2}$, and $3.13 \mathrm{~kg} / \mathrm{hm}^{2}$, respectively.

3.2.2. Core Explanatory Variable. The core explanatory variable of our empirical analysis is land circulation. The existing studies mainly depict the development of land circulation market from two angles: farmer participation rate and land circulation rate. The former refers to the proportion of transfer-out farmers in contacting farmers in a region, and the latter refers to the proportion of transferred farmland area in contracted farmland area in a region. Here, land circulation rate is selected to characterize land circulation, because our research focuses on the influence of land circulation and scale operation on agricultural CRE.

3.2.3. Mediator Variable. Land use scale is the universal metric of scale operation of farmland. This paper characterizes scale operation of farmland with farmland area per labor, i.e., the farmland area divided by the total labor of planting industry in a region.

3.2.4. Control Variables. In addition to land circulation and farmland scale, agricultural CRE is also affected by various factors, such as industry, factor, market, and environment. To prevent estimation errors induced by missing variables, this paper sets a series of control variables, namely, planting structure, farmland area, human capital, product price, effective irrigation rate, agricultural disaster rate, farmer income, urbanization rate, financial support, and policy regulation. Table 1 lists the definitions and calculation methods of all variables.

3.3. Data Sources. The original data mainly come from China Statistical Yearbooks, China Rural Statistical Yearbooks, China Land Resources Database, and the data released by China's National Bureau of Statistics. Specifically, land circulation data were sorted from China Rural Economy Statistical Reports and China Statistical Yearbooks of Rural Operation and Management. The data on rural human 
TABLE 1: Definitions and descriptive statistics of variables.

\begin{tabular}{|c|c|c|c|c|}
\hline Type & Name & Definition and calculation method & Mean & Standard error \\
\hline \multirow{8}{*}{$\begin{array}{l}\text { Explained variable } \\
\text { Key explanatory } \\
\text { variables } \\
\text { Mediator variable }\end{array}$} & Agricultural CRE & Measured by SBM-DEA* & 0.439 & 0.250 \\
\hline & Land circulation & Transferred farmland area/contracted farmland area & 0.216 & 0.170 \\
\hline & Scale operation & Farmland area/total labor in planting industry (hectares/person) & 1.052 & 0.709 \\
\hline & Farmland area & Farmland area $\left(\times 10^{5}\right.$ hectares $)$ & 43.629 & 30.958 \\
\hline & Planting structure & Sown area of food crops/total sown area of all crops & 0.662 & 0.134 \\
\hline & Human capital & Mean years of education in rural areas (years) & 7.533 & 0.683 \\
\hline & $\begin{array}{l}\text { Effective irrigation } \\
\text { rate }\end{array}$ & Effective irrigation area/farmland area & 0.518 & 0.224 \\
\hline & $\begin{array}{l}\text { Agricultural disaster } \\
\text { rate }\end{array}$ & Disaster-affected sown area/total sown area of crops & 0.215 & 0.151 \\
\hline \multirow[t]{6}{*}{ Control variables } & Product price & $\begin{array}{c}\text { Production price index of planting industry in the previous year, } \\
\text { deflated with } 2004 \text { as the base period }\end{array}$ & 1.502 & 0.353 \\
\hline & Production cost & $\begin{array}{l}\text { Price index for agricultural production means in the current year, } \\
\text { deflated with } 2005 \text { as the base period }\end{array}$ & 1.401 & 0.238 \\
\hline & Farmer income & $\begin{array}{l}\text { Per-capita disposable income of rural residents (10,000 yuan), } \\
\text { deflated with } 2005 \text { as the base period }\end{array}$ & 0.673 & 0.365 \\
\hline & Urbanization rate & Urban population/total population & 0.535 & 0.276 \\
\hline & Financial support & Fiscal expenditure on agriculture/total output of AFAF & 15.944 & 21.913 \\
\hline & Policy regulation & $0=$ before $2015 ; 1=$ after 2015 & 0.286 & 0.452 \\
\hline
\end{tabular}

(1) On the human capital in rural areas, the years of education were recorded as 0 year, 6 years, 9 years, 12 years, and 16 years for the illiterate, primary school graduates, junior high school graduates, senior high school graduates, and graduates from junior college and above, respectively. Then, the mean years of education were calculated by dividing the number of people in each group with the total population in rural areas. (2) Since 2015, China launched many green agricultural development policies, such as the Zero-Increase Campaign of Fertilizers and Pesticides, and Farmland Quality Protection and Improvement Action. These policies, which advocate reducing chemical inputs and improving farming methods, are directly related to agricultural carbon emissions.

capital were calculated based on China Population and Employment Statistical Yearbooks. The missing data were supplemented by looking up the statistical yearbooks and statistical bulletins of the relevant provinces. Tibet was excluded from the research because lots of data are missing. Eventually, this paper obtains the balanced panel data about 30 Chinese provinces over the 14 years from 2005 to 2018. The data contain 420 observations.

\section{Empirical Analysis and Results Analysis}

4.1. Evaluation of Agricultural CRE. The proposed SBM$\mathrm{DEA}^{*}$ was solved through linear programming on MaxDEA, and the annual agricultural CRE of each province was measured by formula (2). The annual agricultural CREs of the 30 provinces are reported in Table 2.

In the observation period, Ningxia was the only province experiencing a slight drop in agricultural CRE, while all the other provinces saw their agricultural CREs growing. By annual growth rate, the top five provinces were Shandong, Henan, Jiangsu, Heilongjiang, and Fujian in turn. Most of them are main food producers and major agricultural provinces.

In 2005, only Qinghai and Ningxia reached the efficient frontier of carbon reduction. All the other provinces emitted an excessive amount of agricultural carbon dioxide, to varied degrees. In 2018, Beijing, Shanghai, Shandong, Henan, Heilongjiang, Fujian, Xinjiang, Guangdong, Hainan, Sichuan, Guizhou, and Qinghai reached that frontier.

On the extreme differences between regions, Hebei had the lowest CRE in 2005 (0.099), 10 times lower than the CREs of efficient provinces. Hunan had the lowest CRE in 2018 (0.340), 2.9 times lower than the CREs of efficient provinces. From 2005 to 2018, the CRE gap narrowed significantly.

The mean agricultural CREs of China were derived from the agricultural CREs of the 30 provinces. As shown in Figure 1, the national CRE and its growth rate evolved through three phases: fluctuated zigzag growth (2005-2011), decelerated slow growth (2012-2014), and accelerated rapid growth (2015-2018). Overall, China's agricultural CRE changed from low efficiency to high efficiency in the observation period, but there is still a large space of carbon reduction. The mean agricultural CRE of China was 0.756 in 2018, up by 0.478 from that in 2005 . The annual growth rate was $8.0 \%$. Thus, $24 \%$ of agricultural emissions are yet to be cut down.

4.2. Benchmark Regression. The benchmark model was regressed on Stata 15. This paper utilizes the balanced penal data of 30 Chinese provinces over 14 years. Spurious regression is very unlikely under the sample structure of large size $(\mathrm{N})$ and short time $(\mathrm{T})$. But stationarity test was still carried out to ensure the reliability of our empirical analysis. The results of Im Pesara and Shin (IPS) test on heterogenous unit root show that, except the dummy variable of policy regulation, all the remaining 13 variables rejected the null hypothesis of a unit root at the significance level of $10 \%$.

Furthermore, the variance inflation factor (VIF) method was applied to test the multicollinearity. The mean VIF of explanatory variables was obtained as 3.16, below the threshold of 10 . It can be empirically judged that the variables are not multicollinear. 
TABLE 2: Annual agricultural CREs of 30 Chinese provinces.

\begin{tabular}{|c|c|c|c|c|c|c|}
\hline Province & 2005 & 2010 & 2015 & 2018 & Mean in $2005-2018$ & Annual mean growth rate $(\%)$ \\
\hline Beijing & 0.693 & 0.732 & 0.994 & 1.000 & 0.826 & 2.86 \\
\hline Tianjin & 0.590 & 0.403 & 0.500 & 0.797 & 0.470 & 2.34 \\
\hline Hebei & 0.099 & 0.347 & 0.501 & 0.413 & 0.360 & 11.61 \\
\hline Shanxi & 0.167 & 0.286 & 0.393 & 0.474 & 0.317 & 8.36 \\
\hline Inner Mongolia & 0.185 & 0.233 & 0.460 & 0.560 & 0.333 & 8.89 \\
\hline Liaoning & 0.177 & 0.233 & 0.685 & 0.443 & 0.359 & 7.31 \\
\hline Jilin & 0.173 & 0.215 & 0.336 & 0.364 & 0.253 & 5.89 \\
\hline Heilongjiang & 0.162 & 0.236 & 0.775 & 1.000 & 0.499 & 15.03 \\
\hline Shanghai & 0.678 & 0.889 & 0.788 & 1.000 & 0.836 & 3.03 \\
\hline Jiangsu & 0.147 & 0.369 & 0.870 & 0.992 & 0.539 & 15.82 \\
\hline Zhejiang & 0.151 & 0.238 & 0.356 & 0.520 & 0.288 & 9.98 \\
\hline Anhui & 0.118 & 0.236 & 0.486 & 0.643 & 0.337 & 13.93 \\
\hline Fujian & 0.173 & 0.265 & 0.526 & 1.000 & 0.403 & 14.45 \\
\hline Jiangxi & 0.167 & 0.234 & 0.382 & 0.477 & 0.298 & 8.41 \\
\hline Shandong & 0.146 & 0.386 & 0.500 & 1.000 & 0.430 & 15.95 \\
\hline Henan & 0.148 & 0.407 & 0.397 & 1.000 & 0.423 & 15.83 \\
\hline Hubei & 0.137 & 0.302 & 0.651 & 0.653 & 0.404 & 12.76 \\
\hline Hunan & 0.170 & 0.267 & 0.298 & 0.340 & 0.270 & 5.48 \\
\hline Guangdong & 0.205 & 0.336 & 0.303 & 1.000 & 0.390 & 12.96 \\
\hline Guangxi & 0.162 & 0.297 & 0.322 & 0.808 & 0.320 & 13.16 \\
\hline Hainan & 0.315 & 0.359 & 0.627 & 1.000 & 0.514 & 9.29 \\
\hline Chongqing & 0.243 & 0.362 & 0.592 & 0.704 & 0.444 & 8.53 \\
\hline Sichuan & 0.183 & 0.266 & 0.351 & 1.000 & 0.385 & 13.96 \\
\hline Guizhou & 0.259 & 0.366 & 0.734 & 1.000 & 0.513 & 10.95 \\
\hline Yunnan & 0.159 & 0.227 & 0.293 & 0.430 & 0.261 & 7.95 \\
\hline Shaanxi & 0.169 & 0.303 & 0.358 & 0.895 & 0.386 & 13.68 \\
\hline Gansu & 0.193 & 0.252 & 0.324 & 0.439 & 0.282 & 6.53 \\
\hline Qinghai & 1.000 & 1.000 & 1.000 & 1.000 & 0.995 & 0.00 \\
\hline Ningxia & 1.000 & 0.400 & 0.577 & 0.721 & 0.560 & -2.48 \\
\hline Xinjiang & 0.179 & 0.363 & 0.656 & 1.000 & 0.485 & 14.15 \\
\hline
\end{tabular}

Table 3 presents the results of benchmark regression. Models (1)-(3) estimate the influence of land circulation over agricultural CRE after introducing the control variables, region fixed effects, and time fixed effects, respectively. All the models passed the F-test at the significance of $1 \%$, rejecting the null hypothesis of the absence of individual effects. Hence, the fixed effects models are much better than mixed effects models. Further observation shows that, despite the gradual introduction of the control variables, region fixed effects, and time fixed effects, land circulation always had a positive influence on agricultural CRE and that influence passed the significance test at $1 \%$. This means land circulation generally enhances agricultural CRE. For every $1 \%$ growth of land circulation, the agricultural CRE increased by $0.38 \%$.

According to the estimation results in the presence of control variables, farmland area significantly promotes agricultural CRE. The regions with rich farmland resources trend to have a high agricultural CRE. A possible reason is that a large farmland area brings a large market of agricultural social services, which attracts agricultural service organizations, and deepens the division of labor. More producers access specialized services and realize standard agricultural production. In this way, the technological level of agricultural production is improved.

The coefficient of planting structure was significantly negative, suggesting that agricultural CRE is negatively correlated with the proportion of food crops in the planting structure. In China, the intensive use of chemicals is a common practice to realize a high yield of food crops. That is why agricultural CRE decreases with the growing proportion of food crops in the planting structure.

The coefficient of effective irrigation rate was a significant positive. The improvement of effective irrigation rate means technological advancement and improvement in farmland water conservancy facilities. These two factors facilitate the optimization of agricultural production methods, and in turn enhance CRE.

Farmer income has a significant positive impact on agricultural CRE. Farmer income reflects the level of development of regional economy. Studies have shown that farmers in developed regions are more concerned about agricultural ecological benefits than those in underdeveloped regions.

The coefficient of financial support was significantly negative, suggesting that more fiscal expenditure on agriculture induces the loss of agricultural CRE. A possible explanation is that the financial support will raise the producers' expectation of benefits. The producers will step up factor inputs, which pushes up agricultural carbon emissions.

Policy regulation has significant positive impact on agricultural CRE, indicating that China's green agricultural development policies, such as the Zero-Increase Campaign 


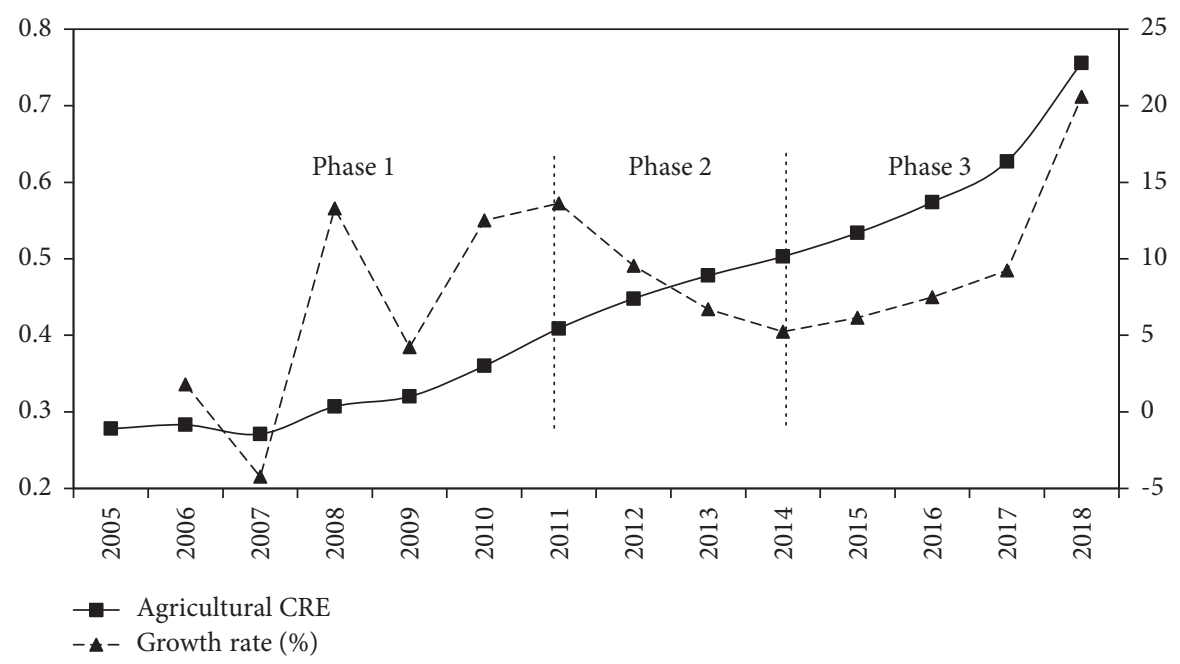

FIgURE 1: China's agricultural CRE trend in 2005-2018.

of Fertilizers and Pesticides, and Farmland Quality Protection and Improvement Action, which were implemented since 2015, have greatly improved agricultural CRE.

Before regional analysis, China was divided into three regions: the eastern region includes Beijing, Tianjin, Hebei, Liaoning, Shanghai, Jiangsu, Zhejiang, Fujian, Shandong, Guangdong, and Hainan. The central region includes Shanxi, Jilin, Heilongjiang, Anhui, Jiangxi, Henan, Hubei, and Hunan. The western region includes Inner Mongolia, Guangxi, Chongqing, Sichuan, Guizhou, Yunnan, Shaanxi, Gansu, Qinghai, Ningxia, and Xinjiang. The statistics of our research show that, from 2005 to 2018, the land circulation rates of eastern, central, and western regions were $0.27,0.22$, and 0.16 , respectively.

In rural China, there is a huge regional difference of land circulation, owing to the disparity of economic foundation and natural endowment. Land circulation in eastern and central regions is much more mature than that in western region. Therefore, this paper further explores the regional difference in how land circulation influences agricultural CRE. The regional regression results are given in Table 4.

The improving effect of land circulation on agricultural CRE varied from region to region. The improving effect was significant in eastern and central regions, but insignificant in western region. It can be inferred that the improving effect of land circulation on agricultural CRE only exists when land circulation falls within a threshold. If the circulation market is incomplete, the factor allocation and division of labor will not proceed smoothly for land circulation. This will weaken and even offset the improving effect of land circulation on agricultural CRE.

4.3. Mediating Effect Testing. Based on benchmark regression, the analysis framework of mediating effect was adopted to test the mediating effect of the path "land circulation-scale operation-agricultural CRE." The estimation results are displayed in Table 5.
Model (7) depicts the impact of land circulation on scale operation of farmland. The coefficient of land circulation on scale operation of farmland was positive, passing the significance test at 5\%. Hence, development of land circulation market significantly promotes the scale operation of farmland, which verifies the views in the previous studies.

Apart from introducing land circulation, models (8) and (9) gradually include the first- and second-order terms of scale operation of farmland in regression and estimate the effects of land circulation and scale operation on agricultural CRE. Compared with those of model (8), the significance levels of variables and goodness-of-fit of model (9) were very high, reflecting the suitability of including the second-order term of scale operation. When both the first- and secondorder terms of scale operation were incorporated, the coefficient of land circulation was positive, that of the firstorder term of scale operation was positive, and that of the second-order term of scale operation was negative. All three passed the significance test at $1 \%$.

The above results indicate that scale operation of farmland has a partial, nonlinear mediating effect on how land circulation influences agricultural CRE. In other words, land circulation not only directly improves agricultural CRE, but also exerts an inverted U-shaped impact on agricultural $\mathrm{CRE}$ via scale operation. On the one hand, land circulation directly improves agricultural CRE by correcting the mismatch between labors and factors. On the other hand, the development of land circulation market indirectly affects agricultural CRE by improving the level of scale operation of farmland. With the expansion of farmlands, agricultural production goes from the realization of scale economy to the dissipation of scale economy. As a result, land circulation firstly promotes and then suppresses agricultural CRE, exhibiting a nonlinear influence.

Further analysis found that the turning point for the nonlinear influence from scale operation of farmland over agricultural CRE was 1.6 hectares/person. In the observation period, a total of 54 samples surpassed that threshold. In 
TABLE 3: Results of benchmark regression.

\begin{tabular}{|c|c|c|c|}
\hline \multirow{2}{*}{ Explanatory variables } & \multicolumn{3}{|c|}{ Agricultural CRE } \\
\hline & Model (1) & Model (2) & Model (3) \\
\hline Land circulation & $1.046^{* * *}(0.051)$ & $0.386^{* * *}(0.119)$ & $0.379^{* * *}(0.121)$ \\
\hline Farmland area & - & $0.005^{* * *}(0.001)$ & $0.003^{* * *}(0.001)$ \\
\hline Planting structure & - & $-0.800^{* * *}(0.197)$ & $-0.589^{* * *}(0.196)$ \\
\hline Human capital & - & $-0.032(0.031)$ & $-0.067(0.036)$ \\
\hline Effective irrigation rate & - & $0.358^{* * *}(0.114)$ & $0.276^{* *}(0.112)$ \\
\hline Agricultural disaster rate & - & $-0.022(0.052)$ & $0.005(0.051)$ \\
\hline Product price & - & $-0.027(0.047)$ & $-0.039(0.063)$ \\
\hline Production cost & - & $0.046(0.073)$ & $-0.140(0.109)$ \\
\hline Farmer income & - & $0.400^{* * *}(0.076)$ & $0.158^{*}(0.088)$ \\
\hline Urbanization rate & - & $-0.004(0.023)$ & $0.003(0.022)$ \\
\hline Financial support & - & $-0.003^{* * *}(0.000)$ & $-0.002^{* * *}(0.000)$ \\
\hline Policy regulation & - & $0.038^{*}(0.022)$ & $0.474^{* * *}(0.116)$ \\
\hline Constant term & $0.213^{* * *}(0.013)$ & $0.479^{* *}(0.245)$ & $0.952^{* * *}(0.326)$ \\
\hline Region fixed effects & YES & YES & YES \\
\hline Time fixed effects & $\mathrm{NO}$ & $\mathrm{NO}$ & YES \\
\hline F-statistic & $22.92^{* * *}$ & $23.01^{* * *}$ & $24.39^{* * *}$ \\
\hline$R^{2}$ & 0.52 & 0.64 & 0.68 \\
\hline Observation & 420 & 420 & 420 \\
\hline
\end{tabular}

The bracketed figures represent standard errors; ${ }^{* * *},{ }^{* *}$, and ${ }^{*}$ indicate that the corresponding variable passes significance test at $1 \%, 5 \%$, and $10 \%$, respectively. The following table also means the same.

TABLE 4: Regional regression results.

\begin{tabular}{|c|c|c|c|}
\hline \multirow[b]{2}{*}{ Explanatory variables } & \multicolumn{3}{|c|}{ Agricultural CRE } \\
\hline & $\begin{array}{c}\text { Eastern region } \\
\text { Model (4) }\end{array}$ & $\begin{array}{c}\text { Central region } \\
\text { Model (5) }\end{array}$ & $\begin{array}{c}\text { Western region } \\
\text { Model (6) }\end{array}$ \\
\hline Land circulation & $0.617^{* * *}(0.147)$ & $0.423^{*}(0.233)$ & $0.018(0.290)$ \\
\hline Control variables & YES & YES & YES \\
\hline Region fixed effects & YES & YES & YES \\
\hline Time fixed effects & YES & YES & YES \\
\hline F-statistic & $15.71^{* * *}$ & $7.67^{* * *}$ & $23.23^{* * *}$ \\
\hline$R^{2}$ & 0.73 & 0.80 & 0.63 \\
\hline Observation & 154 & 112 & 154 \\
\hline
\end{tabular}

TABLE 5: Test results on mediating effect.

\begin{tabular}{lccc}
\hline Explanatory variables & $\begin{array}{c}\text { Scale operation } \\
\text { Model }(7)\end{array}$ & Model $(8)$ & Agricultural CRE \\
\hline Land circulation & $0.292^{* *}(0.118)$ & $0.407^{* * *}(0.121)$ & $0.317^{* * *}(0.121)$ \\
Scale operation & - & $-0.119^{* *}(0.059)$ & $0.353^{* * *}(0.123)$ \\
Square of scale operation & - & - & $-0.112^{* * *}(0.028)$ \\
Control variables & Yes & Yes & Yes \\
Region fixed effects & Yes & Yes & Yes \\
Time fixed effects & Yes & Yes & Yes \\
F-statistic & $329.37^{* * *}$ & $22.29^{* * *}$ & $23.54^{* * *}$ \\
$R^{2}$ & 0.59 & 0.67 & 0.70 \\
Observation & 420 & 420 & 420 \\
\hline
\end{tabular}

2018, Heilongjiang, Jilin, Liaoning, and Inner Mongolia were above that threshold. Overall, the scale operation of farmland in China is generally in the phase of realization of economy scale. It can be expected that, with further development of land circulation, the scale operation of farmland in China will continue to increase. But it is necessary to guard against the CRE loss brought by excessive expansion of farmland scale.
4.4. Robustness Test. To some extent, controlling region and time fixed effects can solve the endogeneity and estimation errors caused by missing variables. However, this strategy cannot effectively overcome the endogeneity arising from sample selection errors and bidirectional causal relationship.

On the one hand, the overall influence of land circulation on agricultural CRE varies from region to region. If the 
TABLE 6: Robustness test results.

\begin{tabular}{lcccc}
\hline Explanatory variables & \multicolumn{3}{c}{ Reducing sample size } & \multicolumn{2}{c}{$\begin{array}{c}\text { Controlling endogeneity } \\
\text { Scale operation } \\
\text { Model }(11)\end{array}$} & $\begin{array}{c}\text { Agricultural CRE } \\
\text { Model (12) }\end{array}$ & $\begin{array}{c}\text { Agricultural CRE with one year lead } \\
\text { Model (13) }\end{array}$ \\
\hline Land circulation & $0.553^{* * *}(0.124)$ & $0.338^{* * *}(0.146)$ & $0.473^{* * *}(0.126)$ & $0.329^{* * *}(0.122)$ \\
Scale operation & - & - & $0.347^{* *}(0.142)$ & $0.445^{* * *}(0.139)$ \\
Square of scale operation & - & - & $-0.101^{* * *}(0.032)$ & $-0.123^{* * *}(0.030)$ \\
Control variables & Yes & Yes & Yes & Yes \\
Region fixed effects & Yes & Yes & Yes & Yes \\
Time fixed effects & Yes & Yes & Yes & Yes \\
F-statistic & $16.94^{* * *}$ & $103.19^{* * *}$ & $16.90^{* * *}$ & $22.22^{* * *}$ \\
$R^{2}$ & 0.75 & 0.63 & 0.77 & 0.70 \\
Observation & 266 & 266 & 266 & 390 \\
\hline
\end{tabular}

region with insignificant influence is included in the regression formula, the mediating effect could be estimated incorrectly. Hence, the samples in the western region were removed for robustness test.

On the other hand, agricultural CRE reflects the cost efficiency of agricultural production to a certain degree. Land circulation and agricultural CRE might have a bidirectional causal relationship. While land circulation affects agricultural CRE, the CRE of producers bears on their participation in land circulation market and level of scale operation. Considering the lack of suitable instrumental variables on the macrolevel, this paper controls the potential endogeneity, using the CRE with one year lead as the explained variable.

Table 6 presents the robustness test results after reducing the sample size and controlling endogeneity. It can be seen that land circulation had an overall significantly positive influence on agricultural CRE, and the path of "land circulation-scale operation-agricultural CRE" was still valid. Hence, our research results are robust.

\section{Conclusions}

Taking the panel data on 30 Chinese provinces in 2005-2018 as samples, this paper quantifies agricultural CREs with SBM-DEA* and establishes an analysis framework of mediating effect. Under this framework, the authors empirically verified the direct influence of land circulation over agricultural CRE, as well as its indirect influence on the latter via scale operation. The results show that the following: (1) In the observation period, China's agricultural CREs generally evolved from a low level to a high level, with an annual growth rate of $8.0 \%$, but there is still a large space of carbon reduction. (2) Overall, land circulation significantly promoted agricultural CRE, but the promoting effect varied from region to region: the promoting effect was significant in eastern and central regions, and insignificant in western region. (3) Scale operation of farmland had a nonlinear, and partial mediation effect on how land circulation influences agricultural CRE; land circulation greatly accelerated the scale operation of farmland, while the growing scale of farmland utilization had an inverted $\mathrm{U}$-shaped influence on agricultural CRE. This conclusion remains robust after reducing sample size and controlling endogeneity.

The above conclusions confirm that land circulation has a two-fold influence on agricultural CRE. China is working to realize the scale economy in agriculture. Land circulation remains an effective path to low-carbon agriculture. However, it is important to guard against the CRE loss brought by excessive expansion of farmland scale. On this basis, crystal clear policy suggestions were obtained:

First, the construction of land circulation market is the gist of optimizing internal factor allocation and deepening professional division of labor in agriculture. The market construction can significantly promote the low-carbon transformation of agriculture. Considering the obvious regional difference in the development of land circulation market, it is necessary to take pertinent measures to cultivate rural land circulation markets: focus on the market in regions with a weak economic foundation and poor transportation conditions, improve land circulation agent platforms, and promote the coordinated development of land circulation markets between regions.

Second, land circulation is a necessary condition for achieving scale operation of farmland. A moderate scale of farmlands could improve agricultural CRE to the greatest extent. On the one hand, the government departments should highlight the moderate development of scale operation, perfect the guidance, monitoring and service system of land circulation and scale operation of farmland, and avoid issuing greedy or hasty policies or industry guidelines. On the other hand, the government departments should reinforce agricultural vocational education, train high-quality professional farmers, and educate entrepreneurial leaders. The agricultural trainings must be directed precisely at the actual needs of different types of subjects of farmland management.

\section{Data Availability}

The data used to support the findings of this study are available from the corresponding author upon request.

\section{Conflicts of Interest}

The authors declare that they have no conflicts of interest. 


\section{Acknowledgments}

This paper was supported by National Natural Science Foundation of China (Grant No.: 71873004); Soft Science Research Project, Anhui Province, China (Grant No.: 201906F01050034); and Philosophical and Social Science Planning Project, Anhui Province, China (Grant No.: AHSKY2018D93).

\section{References}

[1] China Environmental Monitoring Station, China ecological and environmental status bulletin, http://www.cnemc.cn/ jcbg/zghjzkgb/201906/t20190618_706932.shtml, 2018.

[2] J. X. Zhang and H. L. Wang, "Environmental regulation, agricultural technology innovation and agricultural carbon emissions," Journal of Hubei University (Philosophy and Social Science), vol. 47, no. 4, pp. 147-156, 2020.

[3] W. J. Zhao, D. F. Li, and X. E. Wang, "Ideas for the development of low-carbon agriculture," Environmental Protection, vol. 2010, no. 12, pp. 38-39, 2010.

[4] X. Q. Ye, "The 40-year evolution and future trend of my country's agricultural management system," Agricultural economic issues, vol. 2018, no. 6, pp. 8-17, 2018.

[5] Y. H. Wu and X. L. Ma, "Research on the development of land circulation market based on the perspective of external governance environment and internal governance structure," Agricultural economic issues, vol. 2021, no. 5, pp. 66-77, 2021.

[6] Ministry of Agriculture and Rural Affairs of the People's Republic of China, Letter Concerning the Reply to Proposal No. 3063 of the Third Session of the 13th National Committee of the CPPCC, Ministry of Agriculture and Rural Affairs of the People's Republic of China, Beijing, Chinahttp://www.moa. gov.cn/govpublic/zcggs/202009/t20200928_6353471.htm.

[7] J. Chamberlin and J. Ricker-Gilbert, "Participation in rural land rental markets in sub-saharan Africa: who benefits and by how much? Evidence from Malawi and Zambia," American Journal of Agricultural Economics, vol. 98, no. 5, pp. 1507$1528,2016$.

[8] T. S. Liu, "What is the impact of poor farmland circulation on grain production?-_A case study of wheat production in Huanghuaihai agricultural region," China's Rural Economy, vol. 2018, no. 12, pp. 103-116, 2018.

[9] B. K. Chen, N. N. Ma, and D. L. Wang, "Land circulation, agricultural productivity and farmers' income," The World Economy, vol. 43, no. 10, pp. 97-120, 2020.

[10] B. L. Luo, "Farmland right confirmation, transaction implications and the transformation of agricultural management modes--expanding coase theorem and case studies," China's Rural Economy, vol. 2016, no. 11, pp. 2-16, 2016.

[11] Z. H. Yang, "The mechanism and performance evaluation of the impact of rural land circulation on the environment," Journal of Central South University of Forestry and Technology (Social Science Edition), vol. 12, no. 5, pp. 31-36, 2018.

[12] Z. H. Liang, L. Zhang, and J. B. Zhang, "Land transfer, plot size and fertilizer reduction: an empirical analysis based on the main rice producing areas in Hubei Province," China Rural Observation, vol. 2020, no. 5, pp. 73-92, 2020.

[13] Y. P. Kuang and R. Zhang, "The impact of farmland transfer on the eco-efficiency of food production," China's population, resources and environment, vol. 31, no. 4, pp. 172-180, 2021.

[14] Y. H. Li, "Analysis of the externalities of agricultural largescale operation-—a survey from the perspective of ecological environment," Journal of Chongqing University of Technology (Social Sciences), vol. 30, no. 7, pp. 37-43, 2016.

[15] Y. H. Shan, L. N. Wang, and M. J. Li, "Analysis on the path of farmers' low-carbon management under the trend of socialized small farmers-_taking Hubei province as an example," Resources and Environment in the Yangtze River Basin, vol. 29, no. 11, pp. 2479-2487, 2020.

[16] S. H. Ye, Z. H. Qi, W. H. Huang, and K. Liu, "Business scale, acquisition of information technology and farmer's ecological production behavior-- analysis of the difference of different production behaviors and farmer types," Journal of China Agricultural University, vol. 24, no. 3, pp. 173-186, 2019.

[17] Q. Liu and H. F. Xiao, "What is the logic of the scale of farmland management affecting agricultural carbon emissions? - - the mediating role of factor input and the regulating role of cultural quality," Rural Economy, vol. 2020, no. 5, pp. 10-17, 2020.

[18] Y. Cheng, K. Lv, J. Wang, and H. Xu, "Energy efficiency, carbon dioxide emission efficiency and related abatement costs in regional China: a synthesis of input-output analysis and DEA," Energy Efficiency, vol. 12, no. 4, pp. 1-15, 2019.

[19] D. Liang, Z. Tian, F. Ren, and J. Pan, "Installed hydropower capacity and carbon emission reduction efficiency based on the EBM method in China," Frontiers in Energy Research, vol. 8, p. 82, 2020 .

[20] S. Tan, N. Heerink, and F. Qu, "Land fragmentation and its driving forces in China," Land Use Policy, vol. 23, no. 3, pp. 272-285, 2006.

[21] M. R. R. Tabari, S. Sabzalipour, S. M. Peyghambarzadeh, and R. Jalilzadeh, "Dispersion of volatile organic compounds in the vicinity of petroleum products storage tanks," Environmental Engineering \& Management Journal (EEMJ), vol. 20, no. 7, pp. 1119-1136, 2021.

[22] Y. X. Bai and P. Liu, "The historical evolution of rural labor mobility since the founding of New China--based on the perspective of promoting the household contract responsibility system," Fujian Tribune, vol. 2019, no. 3, pp. 5-14, 2019.

[23] Q. E. Gai, M. W. Cheng, X. Zhu, and Q. H. Shi, "Can land rent improve land Allocation's efficiency? - - evidence from national fixed point survey," China Economic Quarterly, vol. 20, no. 5, pp. 321-340, 2020.

[24] T. S. Liu and G. Wu, "Income loss of misallocation of farmland resources: an econometric analysis based on farmers' willingness to adjust farmland scale," Journal of Nanjing Agricultural University (Social Sciences Edition), vol. 19, no. 6, pp. 107-118+159, 2019.

[25] M. L. Song and P. Z. Jin, "Regional protection, resource misallocation and environmental welfare performance," Economic Research Journal, vol. 51, no. 12, pp. 47-61, 2016.

[26] K. Deininger and S. Jin, "Land sales and rental markets in transition: evidence from rural Vietnam," Oxford Bulletin of Economics and Statistics, vol. 70, no. 1, pp. 67-101, 2008.

[27] R. Fei, Z. Lin, and J. Chunga, "How land transfer affects agricultural land use efficiency: evidence from China's agricultural sector," Land Use Policy, vol. 103, Article ID 105300, 2021.

[28] Y. P. Kuang and J. L. Yang, “Analysis of China's agricultural technical efficiency from the perspective of agricultural land transfer," Journal of Nanjing Agricultural University (Social Sciences Edition), vol. 18, no. 2, pp. 138-148, 2018.

[29] F. X. Yang and X. X. Wang, "Effects of irrigation water price and technological progress on the intensity of water use in agriculture: an empirical study of three main grains," Research 
of Agricultural Modernization, vol. 42, no. 4, pp. 735-744, 2021.

[30] E. M. Rogers, Diffusion of Innovations, Simon and Schuster, New York, NY, USA, 5th edition, 2003.

[31] X. Y. Zheng, F. Wang, and R. Y. Ying, "Farmers' endowment constraints, technical properties and agricultural technology selection preferences: an Analytical framework of farmers' technology adoption under an incomplete factor market," Chinese Rural Economy, vol. 2018, no. 3, pp. 105-122, 2018.

[32] B. Song, Y. Y. Mu, and L. L. Hou, "Study on the effect of farm households' specialization on low-carbon agriculture:evidence from vegetable growers in beijing, China," Journal of Natural Resources, vol. 31, no. 3, pp. 468-476, 2016.

[33] Y. Liu, L. Zhang, Z. H. Liang, and J. B. Zhang, "Bounded rationality, low-carbon agricultural technology and farmers' Strategic Choice-a game analysis from the perspective of farmers," World Agriculture, vol. 2019, no. 9, pp. 59-68, 2019.

[34] X. Bao and X. Xing, "Evaluation of green logistics system of solid waste at ports based on analytic hierarchy process," Environmental Engineering and Management Journal, vol. 18, no. 11, pp. 2491-2499, 2019.

[35] Y. Guo and Z. G. Xu, "Cultivated land circulation market development, resource endowment and agricultural land scale management development," Chinese Rural Economy, vol. 6, pp. 60-75, 2021.

[36] L. Zhang and B. L. Luo, "Agricultural Chemical Reduction: The Logic and Evidence Based on Farmland Operation Scale of Households," Chinese Rural Economy, vol. 2, pp. 81-99, 2020.

[37] Y. Yang, R. Li, and M. F. Wu, "The constraints of land fragmentation on farmers' agricultural machinery services purchase," Journal of Agrotechnical Economics, vol. 10, pp. 17-25, 2018.

[38] H. N. Song, J. D. Luan, S. Y. Zhang, and J. Y. Jiang, "Land Fragmentation, Production diversification and agricultural production technical efficiency-_empirical analysis based on stochastic frontier production function and mediation model," Journal of Agrotechnical Economics, vol. 2, pp. 18-29, 2021.

[39] X. H. Zhang, Y. H. Zhou, and B. J. Yan, "Scale of farmland operation and cost of rice production: a case study of Jiangsu province," Issues in Agricultural Economy, vol. 38, no. 2, pp. $48-55+2,2017$.

[40] C. Y. Zhang, Q. Chang, and X. X. Huo, "Can the moderatescale management really reduce the production costs of agricultural products?-an empirical analysis based on 661 Shaanxi Apple farmers," Journal of Agrotechnical Economics, vol. 10, pp. 26-35, 2018.

[41] X. He, T. Jiang, L. Y. Guo, and L. Gan, "Research on the development of China's farmland transfer market and farmers' land transfer behavior: based on the farmer survey data of 29 provinces from 2013 to 2015," Management World, vol. 6, pp. 79-89, 2016.

[42] K. Tone, "Dealing with undesirable outputs in DEA: a slacksbased measure (SBM) Approach," pp. 44-45, Presentation At NAPW III, New York, NY, USA.

[43] H. Y. Wu, H. J. Huang, Y. He, and W. K. Chen, "Measurement, spatial spillovers and influencing factors of agricultural carbon emission efficiency in China," Chinese Journal of EcoAgriculture, 2021.

[44] D. S. Li, Z. Q. Zhang, L. Fu, and S. D. Guo, "Regional differences in PM2.5 emission reduction efficiency and their influencing mechanism in Chinese cities," China Population Resources and Environment, vol. 31, no. 4, pp. 74-85, 20201.
[45] Y. H. Cheng and J. Y. Cheng, "Yangtze River Economic Belt Logistics $\mathrm{CO}_{2}$ Emission reduction efficiency measurement and root cause decomposition," Systems Engineering, vol. 2021, no. 4, pp. 94-102, 2021.

[46] J. T. Pastor and C. A. K. Lovell, "A global Malmquist productivity index," Economics Letters, vol. 88, no. 2, pp. 266-271, 2005.

[47] R. M. Baron and D. A. Kenny, "The moderator-mediator variable distinction in social psychological research: conceptual, strategic, and statistical considerations," Journal of Personality and Social Psychology, vol. 51, no. 6, pp. 1173$1182,1986$.

[48] H. Li, X. B. Wang, and Y. J. Ren, "Comparative analysis of the mechanism of mediation effects-_evidence from farmers' income and health," Journal of Agrotechnical Economics, vol. 2019, no. 9, pp. 58-72, 2019.

[49] X. L. Ma, X. C. Che, N. Li, and L. Tang, "Has cultivated land transfer and scale operation improved the agricultural environment? An empirical test on impact of cultivated land use on agricultural environment efficiency," China Land Science, vol. 33, no. 6, pp. 62-70, 2019. 